\title{
$\mathrm{R} C \& \mathrm{C}$
}

REVISTA DE CONTABILIDADE E CONTROLADORIA

\section{A PER CEPÇÃO DOS ESTUDANTES DE CIÊNCIAS CONTÁBEIS SOBRE SEUS CONHECIMENTOS EM CONTROLADORIA}

\author{
PERCEPTION OF ACCOUNTING STUDENTS ABOUT THEIR KNOWLEDGE IN CONTROLLERSHIP
}

Recebido em 12.03.2015 | Aceite final em 14.01.2016|

Nota: este artigo foi aceito pelo Editor Jorge Eduardo Scarpin e passou por uma avaliação

double blind review

A reprodução dos artigos, total ou parcial, pode ser feita desde que citada a fonte.

ROBERTA SARTORATTO

Graduanda em Ciências Contábeis na Universidade Federal de Santa Catarina | Rua Lauro Linhares, 689, Bloco B9, Apto 201 - Trindade | Florianópolis/SC - Brasil | CEP: 88036-001 | Telefone: (48) 96621826 | E-mail: roberta.sartoratto@ gmail.com |

ROGÉRIO JOÃO LUNKES Professor do Departamento de Ciências Contábeis e do Programa de Pós-Graduação em Contabilidade e Administração da Universidade Federal de Santa Catarina | Rua Lauro Linhares, 1346, Apto 1102 - Trindade | Florianópolis/SC - Brasil | CEP: 88036-002 | Fone: (48) 33343245 | E-mail: rogeriolunkes@ hotmail.com |

FABRICIA SILVA DA ROSA Professora do Departamento de Ciências Contábeis e do Programa de PósGraduação em Contabilidade da Universidade Federal de Santa Catarina | Rua Lauro Linhares, 1346, Apto 1102 - Trindade | Florianópolis/SC - Brasil | CEP: 88036-002 | Fone: (48) 33343245 | E-mail: fabriciasrosa@hotmail.com |

\section{RESUMO}

O presente artigo busca identificar as percepções dos estudantes de Ciências Contábeis sobre seus conhecimentos das funções da controladoria e as características que compõe o seu perfil, a fim de verificar se eles se enquadram nos padrões exigidos pelo mercado brasileiro. $O$ estudo foi realizado através da aplicação de questionários aos acadêmicos da disciplina de Controladoria, dos períodos diurno e noturno, da Universidade Federal de Santa Catarina-Brasil. Os resultados demonstram que apesar do conhecimento técnico ser apresentado através das disciplinas, os estudantes não se sentem confiantes para atuar como controllers. E ainda, foi possível perceber que as características pessoais desejadas pelas empresas não estão presentes nos perfis dos acadêmicos.

Palavras-chaves: Controladoria. Funções. Percepção. Estudantes. 


\begin{abstract}
This article seeks to identify the perceptions of accounting students about their knowledge of controllership functions and the particulars that make up their profile, in order to verify if the students fit the standards required by the brazilian market. The study was conducted through questionnaires applied to the students of Controllership discipline, diurnal and nocturnal, of the Federal University of Santa Catarina - Brazil. The results show that besides the technical knowledge to be presented in the discipline, the students do not feel confident to work as controllers. In addition, it was revealed that the personal characteristics required by the companies are not present in the academic profiles.
\end{abstract}

Keywords: Controllership. Functions. Perception. Students.

\title{
1 INTRODUÇÃO
}

O desenvolvimento das práticas de planejamento e controle, associado à evolução do ambiente econômico e à necessidade de informações e conhecimento favoreceu o surgimento de um novo profissional, o controller como parceiro de negócios. Lunkes e Schnorrenberger (2009) apontam que, inicialmente, as principais tarefas desempenhadas pelo controller eram relacionadas essencialmente à contabilidade e controles financeiros. A pesquisa realizada por Siqueira e Soltelinho (2001) mostra que no início dos anos de 1960 as empresas brasileiras já buscavam por profissionais de controladoria, com formação na área de contabilidade ou economia. A solicitação de controllers, com formação na área de contabilidade, ainda é predominante nas ofertas de vagas por empresas brasileiras (ORO ET AL., 2009; SOUZA e BORINELLI, 2009; FERRARI ET AL., 2013; GOMES, SOUZA e LUNKES, 2014).

Nas últimas décadas, o dinamismo e a complexidade das organizações modificaram o escopo de atuação da Controladoria, que passou a atuar como fornecedora de informações econômicas e financeiras com a finalidade de promover a eficiência e eficácia do processo gerencial e proteção dos interesses da organização (BEUREN, 2000). Ferrari et al. (2013) afirmam que essas mudanças passaram a exigir dos profissionais envolvidos, o desenvolvimento de novas e mais específicas funções e, que em decorrência disso, eles acabaram por assumir novas atribuições e demandar novas competências.

Os novos desenvolvimentos nas organizações tiveram lugar em termos de alcance das atividades (estratégia, risco, sustentabilidade), orientação futura (por exemplo, alerta antecipada) e o papel do controller (proativo, corresponsável). Neste cenário, a controladoria passa a ser o fator chave de sucesso, deixando de ser meramente um fornecedor de informações, e engloba funções vitais inerentes ao planejamento e controle estratégico, sendo o responsável pela coordenação do alinhamento dos objetivos e metas, conteúdo da informação e sistemas de incentivos e motivação, com apoio direto a tomada de decisão dos diversos setores da organização (ICV-IGC, 2013).

A atribuição de uma visão multidisciplinar ao controller nas organizações, abriu caminho para que profissionais de outras áreas de conhecimento, passassem a atuar na Controladoria. As pesquisas sobre o perfil de controllers solicitados por empresas brasileiras, como a realizada por Gomes, Souza e Lunkes (2014), destacam que as vagas de controladoria estão deixando de ser destinadas exclusivamente aos contadores, mesmo que esses ainda sejam os mais requisitados. 
O perfil solicitado para os profissionais da controladoria está mudando com o passar dos anos. Está deixando de ser uma função essencialmente contábil, para ser um profissional estratégico, participante da gestão de forma sistemática, com liderança, pró-atividade e capacidade analítica (GOMES, SOUZA e LUNKES, 2014). Diante dessas novas perspectivas do mercado com relação ao controller, suas funções, atribuições, perfil e competências, o presente estudo apresenta a seguinte questão de pesquisa: qual a percepção dos alunos de graduação em Ciências Contábeis em relação às funções e competências exigidas do controller pelo mercado de trabalho? Para responder a esta questão tem-se como objetivo identificar as percepções dos estudantes de Ciências Contábeis sobre seus conhecimentos das funções da controladoria requeridas pelo mercado de trabalho brasileiro.

A pesquisa é relevante, pois busca identificar as percepções dos estudantes de Ciências Contábeis sobre seus conhecimentos das funções da controladoria requeridas pelo mercado de trabalho brasileiro. Além de apresentar as características exigidas pelo mercado, indicando para aqueles com interesse de atuar na área, os principais conhecimentos exigidos pelo mercado para a profissão.

\section{REFERENCIAL TEÓRICO - CONTROLADORIA 2.1 FUNÇÕES DA CONTROLADORIA}

As funções têm como objetivo orientar o campo de atuação de determinada área do conhecimento. São como a ação própria ou natural de um órgão, aparelho ou máquina (LUNKES, SCHNORRENBERGER e ROSA, 2013). Entre as funções apontadas na administração clássica temos o planejamento, organização, direção e controle.

A controladoria é um campo que está tentando consolidar um conjunto básico de funções que orientam os estudos e pesquisas na área e, consequentemente as disciplinas acadêmicas e a sua aplicação prática nas organizações. Na última década, tem crescido a quantidade de estudos relacionados às funções da controladoria (GIONGO e NASCIMENTO, 2005; CALIJURI, SANTOS e SANTOS, 2005; SANTOS ET AL., 2005; BORINELLI, 2006; DANIEL, DAL VESCO e TARIFA, 2007; OLIVEIRA e PONTE, 2006; SCHNORRENBERGER ET AL., 2007; SANTOS ET AL., 2008; FACHINI, BEUREN e NASCIMENTO, 2009; MEDEIROS e RABELLO, 2010; e LUNKES ET AL., 2011, WEBER, 2011; LUNKES, SCHNORRENBERGER e ROSA, 2013).

O ICV - Internationaler Controller Verein e o IGC - International Group of Controlling têm definido a controladoria como uma atividade de gestão. Significa que é orientada a objetivos e para coordenar todas as decisões para a consecução deste fim. Consequentemente, planejamento e execução das práticas, bem como o monitoramento e controle, são de importância central. Isto pode ser aplicado a cada decisão de gestão individual, bem como para a gestão da organização como um todo (ICV-IGC, 2013).

Weber (2011) classificou as funções em dois grandes grupos: funções do contador de feijão e funções do parceiro de negócios, conforme Figura 1. 
Figura 1: Principais funções do controller na visão do contador de feijão e do parceiro de negócios

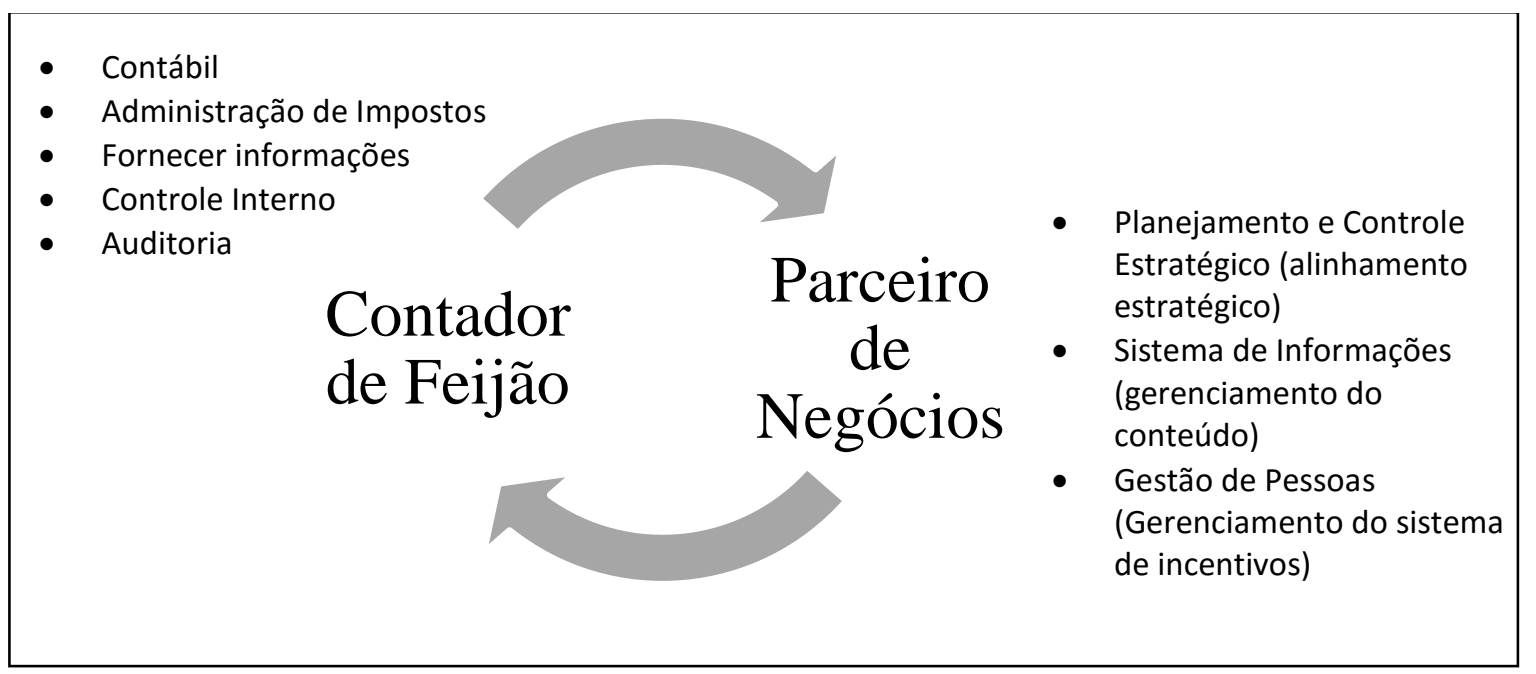

A Figura 1 apresenta funções básicas do contador de feijão e do parceiro de negócios. No grupo do contador de feijão são classificados aqueles que exerçam funções básicas como elaboração de relatórios contábeis, controle da demonstração do resultado do exercício, fluxo de caixa, balanços, controle de custos, fechamento de planilhas, contratos, validação e inclusão de dados no sistema, atuação na interpretação da legislação, organização de documentos, atuação no estudo de viabilidade financeira, controle orçamentário, entre outras.

O parceiro de negócios é aquele que participa mais ativamente nas tomadas de decisões da organização, tendo uma atuação proativa mais estratégica de apoio e tomada de decisão com outros gestores. As funções exercidas pelo parceiro de negócios compreendem o gerenciamento do sistema de informações, o planejamento e o controle estratégico, a participação efetiva na elaboração do plano estratégico em conjunto com as unidades de negócio, a gestão da equipe visando à obtenção do máximo rendimento por meio das práticas de gestão da organização, suporte às equipes gerenciais na tomada de decisão, entre outras funções de caráter mais estratégico.

Para o ICV-IGC (2013), as competências essenciais do profissional que atua nessa área são as seguintes:

- Habilidades analíticas (raciocínio lógico);

- Habilidades de comunicação;

- Conhecimento do negócio;

- Conhecimento comportamental (capacidade de análise psicológica);

- Conhecimento de sistemas de mensuração e avaliação;

- Firmeza (atributo básico e indispensável).

A responsabilidade pela sincronização entre as diversas atividades dos setores distintos da empresa é uma atribuição do controller (MOSIMANN e FISCH, 1999). 


\subsection{A DISCIPLINA DE CONTROLADORIA}

Pereira et al. (2005) descrevem que, em 1999, foi publicada pela Comissão de Especialistas do Ensino de Ciências Contábeis - CEE/Contábeis uma proposta relativa ao perfil profissional e as competências e habilidades necessárias aos formandos em Ciências Contábeis, para o efetivo cumprimento da função dos agentes econômicos de prestar contas à sociedade (accountability). Essa comissão elaborou uma recomendação de conteúdos obrigatórios à formação básica e profissional. Os conteúdos são referentes à área do conhecimento e não refletem os nomes das disciplinas. Segue no Quadro 1 síntese das recomendações definidas para o conteúdo de Controladoria.

Quadro 1: Resumo do conteúdo obrigatório proposto pela CEE/Contábeis para Controladoria

\begin{tabular}{|l|c|}
\hline Conteúdo & Tópicos \\
\hline \multirow{3}{*}{ Controladoria } & - Sistemas de Informação \\
& - Planejamento, Execução e Controle \\
& - Avaliação de Desempenho \\
& - Accountability \\
\hline
\end{tabular}

Fonte: Adaptado de Lunkes et al. (2012)

De acordo com Lunkes et al. (2009), a Controladoria tornou-se cadeira integrante da grade curricular do curso de graduação em Ciências Contábeis através da Resolução CNE/CES 10 de 16 de dezembro de 2004. A Resolução, que institui as diretrizes curriculares nacionais, descreve em seu art. 50, inciso I, que os cursos de graduação em Ciências Contábeis deverão contemplar como conteúdos de formação profissional: estudos específicos atinentes às Teorias da Contabilidade, incluindo as noções das atividades atuariais e de quantificações de informações financeiras, patrimoniais, governamentais e não governamentais, de auditorias, perícias, arbitragens e controladoria, com suas aplicações peculiares ao setor público e privado.

Na pesquisa realizada por Lunkes et al. (2009), que tem como objetivo analisar o comportamento das IES do Sul do Brasil quanto à inclusão da disciplina de controladoria no currículo de Ciências Contábeis, é possível identificar através das ementas da disciplina de controladoria disponibilizadas pelas IES que há grande preocupação na capacitação e profissionalização dos graduandos em temas relacionados à gestão empresarial. Peleias et al. (2011) corroboram com a afirmação ao dizer que a disciplina de controladoria exige a inter-relação com outras áreas do conhecimento.

\subsection{ESTUDOS SOBRE FUNÇÕES EXIGIDAS PELO MERCADO}

Nas últimas décadas, foram realizados inúmeros estudos empíricos sobre funções da controladoria/controller. Visando abordar as funções exigidas na seleção de controller, o estudo irá focar em pesquisas sobre o mercado de trabalho, ou seja, o que as empresas solicitam quando contratam um profissional para a área de controladoria.

Oro et al. (2009) elaboraram uma pesquisa com três empresas especializadas em recrutamento e recursos humanos (Catho, Manager e Michael Page), com objetivo de investigar o perfil de competências do profissional de controladoria em três níveis: operacional, gerencial e estratégico. 0 período analisado foi de agosto a setembro de 2006, totalizando 373 anúncios. Os resultados mostram que o profissional precisa dominar a língua inglesa, conhecer os princípios contábeis americanos, e que a tecnologia de informação representa um instrumento imprescindível.

Souza e Borinelli (2009) buscaram identificar as funções do controller, os pré-requisitos necessários para função e a aderência das funções preconizadas pela teoria com as exigidas na prática. A 
pesquisa foi realizada em três sites (Hays Brasil, Case Consulting e Hays Brasil), no período de 01 de julho a 15 de julho. Os resultados apontaram que a região que mais ofertou vagas foi a sudeste; a formação mais desejada em ciências contábeis; e as funções mais exigidas são gerencial-estratégicas, gestão da informação e contábil.

O estudo de Maciel e Lima (2011) identificou o perfil do controller, levando em consideração as necessidades do mercado por meio da análise de artigos científicos que tratam deste assunto, além de entrevistas com profissionais da área de controladoria. Os resultados evidenciaram que o mercado recruta profissionais com conhecimento de capital humano, capacidade de gerenciar pessoas, espírito de liderança e domínio de línguas.

Ferrari et al. (2013) descreveram as características das funções do controller solicitadas por meio dos anúncios de recrutamento da Revista Exame, referentes aos anos de 2005 a 2012. As funções mais exigidas pelas organizações são: gerenciamento da contabilidade, orçamento e controle fiscal/tributário. Por outro lado, as menos exigidas são: interface com as áreas operacionais e processos administrativos. Em relação às competências, as mais exigidas são visão global do mercado, dinamismo e liderança.

O estudo de Gomes, Souza e Lunkes (2014) identificou o perfil do controller solicitado por empresas brasileiras. Foram analisados 457 anúncios divulgados em cinco sites de recrutamento (Michael Page, Catho, Manager, Case Consulting e Hays Brasil). Os resultados mostram que o mercado procura controllers formados principalmente em Ciências Contábeis, com conhecimento em tecnologia da informação e contabilidade internacional. Profissionais que participam da gestão de forma sistêmica, com liderança, pró-atividade e capacidade analítica.

Esses trabalhos exploram o perfil do controller em vagas oferecidas por empresas de recrutamento, mas não há estudos que verificam a relação com os conhecimentos transmitidos na disciplina de controladoria. Assim, este trabalho contribui para preencher esta lacuna.

\section{METODOLOGIA DE PESQUISA}

Esta seção do trabalho possui como proposta apresentar os procedimentos metodológicos utilizados para a estruturação do referencial teórico, coleta dos dados e análise dos resultados.

O processo de estruturação do referencial teórico consiste na coleta de artigos, selecionados através de um conjunto de parâmetros predeterminados, como palavras-chave e exame do título, resumo, e do texto na íntegra, para confirmar o seu alinhamento com o objetivo de estudo do presente trabalho. A fim de encontrar artigos com reconhecimento científico, as bases de dados selecionadas foram o Portal de Periódicos da Capes, Scielo e Scopus. Além dos artigos científicos, foram utilizadas obras literárias constantes do plano de ensino da disciplina de Controladoria ministrada na Universidade Federal de Santa Catarina - UFSC, no ano de 2014.

A partir das bases de dados citadas acima, as pesquisas foram realizadas utilizando-se da ferramenta de palavras-chave. As palavras-chave utilizadas foram: "controller's functions"; "funções controladoria"; "controllership"; "controladoria" + "ensino superior"; "controladoria" + "disciplina"; "controller" + "mercado" e demais combinações relacionadas ao tema.

O presente estudo utiliza a pesquisa descritiva para alcançar seus objetivos. De acordo com Raupp e Beuren (2003), a pesquisa descritiva pretende identificar, relatar e comparar as variáveis da amostra.

A coleta de dados foi realizada através da aplicação de questionários. O modelo é composto por oito questões, baseadas na revisão de literatura; três de identificação do acadêmico, para posterior seleção dos que se enquadram ao perfil desejado; e as cinco restantes relacionadas ao tema objeto 
de estudo da pesquisa. O questionário foi aplicado em sala de aula, nos dias 5 e 7 de novembro de 2014, aos acadêmicos da disciplina de Controladoria, dos períodos diurno e noturno, da Universidade Federal de Santa Catarina.

Os acadêmicos selecionados para a coleta dos dados da pesquisa estavam cursando as fases finais da graduação em Ciências Contábeis, estas representadas pela oitava e nona fase do curso. Dos 44 questionários preenchidos corretamente, quatro não se enquadravam nas características necessárias para o êxito da pesquisa e foram excluídos. Sendo assim, os resultados obtidos neste estudo são baseados nas respostas de 40 questionários.

A pesquisa, quanto à abordagem do problema, pode ser classificada como quantitativa e qualitativa. A abordagem quantitativa refere-se à coleta de informações, segundo Richardson et al. (2008), ela é caracterizada, dentre outros aspectos, pelo tratamento das informações por meio de técnicas estatísticas, ainda que as mais simples como percentual, média e desvio-padrão. A metodologia qualitativa, de acordo com Lakatos e Marconi (2007), está relacionada à análise e interpretação dos dados coletados de forma mais detalhada, descrevendo a complexidade do comportamento humano.

Cabe ressaltar que os resultados se delimitam à amostra estudada e aos aspectos analisados, que são somente os constantes no questionário aplicado. Sendo necessária, para a averiguação de quaisquer outros aspectos, a realização de um novo estudo.

\section{ANÁLISE DOS RESULTADOS}

A Tabela 1, formulada com as respostas obtidas através dos questionários, apresenta as disciplinas cursadas pelos acadêmicos para que seja possível comparar, em sequência, se o conteúdo teoricamente apresentado em cada uma delas é refletido no nível de confiança dos alunos para coordenar certas atividades gerenciais em uma empresa.

Tabela 1: Disciplinas cursadas

\begin{tabular}{|c|c|c|}
\hline Disciplina & Cursada & $\%$ \\
\hline Contabilidade Gerencial & 40 & 100,0 \\
\hline Custos Gerenciais ou Análise de Custos & 39 & 97,5 \\
\hline Planejamento Tributário & 25 & 62,5 \\
\hline Controladoria ou Controle Gerencial & 29 & 72,5 \\
\hline Planejamento Estratégico & 6 & 15,0 \\
\hline Orçamento ou Planejamento Financeiro & 27 & 67,5 \\
\hline Simulação Gerencial & 39 & 97,5 \\
\hline Sistemas de Informações & 35 & 87,5 \\
\hline
\end{tabular}

Fonte: Dados da pesquisa.

Entre as disciplinas listadas na Tabela 1, todos os acadêmicos já cursaram Contabilidade Gerencial, em sequência, as disciplinas mais cursadas foram Custos Gerenciais ou Análises de Custos e Simulação Gerencial (97,5\%); Sistemas de Informações (87,5\%); Controladoria ou Controle Gerencial (72,5\%); Orçamento ou Planejamento Financeiro (67,5\%); Planejamento Tributário (62,5\%); Planejamento Estratégico (15\%).

É importante destacar que as nomenclaturas utilizadas para as disciplinas listadas não refletem exatamente às constantes nos planos de ensino da instituição em questão, visto que elas podem diferir de uma instituição para outra. Sendo assim, os nomes se referem à temática principal abordada nas disciplinas. 
Na Tabela 2, é possível notar a percepção dos graduandos com relação ao nível de conhecimento para atuar nas atividades listadas. As respostas foram divididas em cinco categorias no qual o nível mais baixo é representado por "não tem conhecimento" e o mais alto por "pleno conhecimento".

Tabela 2: Nível de conhecimento por atividades executadas por controllers

\begin{tabular}{|c|c|c|c|c|c|}
\hline \multirow[b]{2}{*}{ Atividades } & \multicolumn{5}{|c|}{ Nível de Conhecimento } \\
\hline & $\begin{array}{c}\text { Não tem } \\
\text { conhecime } \\
\text { nto }\end{array}$ & $\begin{array}{c}\text { Pouco } \\
\text { conhecime } \\
\text { nto }\end{array}$ & $\begin{array}{c}\text { Conhecim } \\
\text { ento } \\
\text { Básico } \\
\end{array}$ & $\begin{array}{c}\text { Muito } \\
\text { Conhecim } \\
\text { ento }\end{array}$ & $\begin{array}{c}\text { Pleno } \\
\text { Conhecim } \\
\text { ento }\end{array}$ \\
\hline Sistema contábil & $5,0 \%$ & $37,5 \%$ & $37,5 \%$ & $17,5 \%$ & $2,5 \%$ \\
\hline Gerenciar os tributos & $25,0 \%$ & $42,5 \%$ & $22,5 \%$ & $10,0 \%$ & $0,0 \%$ \\
\hline $\begin{array}{l}\text { Planejar, executar e controlar o } \\
\text { orçamento }\end{array}$ & $10,0 \%$ & $37,5 \%$ & $37,5 \%$ & $12,5 \%$ & $2,5 \%$ \\
\hline Fornecer informações aos gestores & $5,0 \%$ & $20,0 \%$ & $52,5 \%$ & $17,5 \%$ & $5,0 \%$ \\
\hline Avaliar as propostas de investimentos & $17,5 \%$ & $32,5 \%$ & $42,5 \%$ & $7,5 \%$ & $0,0 \%$ \\
\hline Controle interno & $12,5 \%$ & $42,4 \%$ & $30,0 \%$ & $10,0 \%$ & $5,0 \%$ \\
\hline Auditoria & $15,0 \%$ & $40,0 \%$ & $42,5 \%$ & $2,5 \%$ & $0,0 \%$ \\
\hline Sistema de custos & $7,5 \%$ & $30,0 \%$ & $47,5 \%$ & $10,0 \%$ & $5,0 \%$ \\
\hline Avaliação financeira & $7,5 \%$ & $37,5 \%$ & $42,5 \%$ & $10,0 \%$ & $2,5 \%$ \\
\hline $\begin{array}{l}\text { Coordenar o desenvolvimento do } \\
\text { planejamento estratégico }\end{array}$ & $30,0 \%$ & $37,5 \%$ & $30,0 \%$ & $0,0 \%$ & $2,5 \%$ \\
\hline Coordenar o alinhamento estratégico & $35,0 \%$ & $45,0 \%$ & $17,5 \%$ & $2,5 \%$ & $0,0 \%$ \\
\hline Implementar o planejamento estratégico & $35,0 \%$ & $55,0 \%$ & $7,5 \%$ & $2,5 \%$ & $0,0 \%$ \\
\hline Gerenciar o conteúdo da informação & $22,5 \%$ & $42,5 \%$ & $25,0 \%$ & $10,0 \%$ & $0,0 \%$ \\
\hline Gerenciar o controle estratégico & $27,5 \%$ & $55,0 \%$ & $10,0 \%$ & $5,0 \%$ & $2,5 \%$ \\
\hline Propor novos investimentos & $17,5 \%$ & $52,5 \%$ & $17,5 \%$ & $12,5 \%$ & $0,0 \%$ \\
\hline $\begin{array}{l}\text { Criar um sistema de } \\
\text { incentivos/motivação }\end{array}$ & $30,0 \%$ & $32,5 \%$ & $32,5 \%$ & $2,5 \%$ & $2,5 \%$ \\
\hline Alinhamento dos objetivos e metas & $17,5 \%$ & $45,0 \%$ & $32,5 \%$ & $2,5 \%$ & $2,5 \%$ \\
\hline Avaliação financeira e não financeira & $12,5 \%$ & $35,0 \%$ & $45,0 \%$ & $7,5 \%$ & $0,0 \%$ \\
\hline $\begin{array}{l}\text { Auxiliar na tomada de decisão dos } \\
\text { gestores }\end{array}$ & $5,0 \%$ & $37,5 \%$ & $47,5 \%$ & $7,5 \%$ & $2,5 \%$ \\
\hline
\end{tabular}

Fonte: Dados da pesquisa.

Ferrari et al (2013), ao pesquisar os anúncios de vagas de controladoria, verificou que as funções mais solicitadas são o gerenciamento da contabilidade, relatórios gerenciais, funções de controle fiscal/tributário, gerenciamento da tesouraria, orçamento e planejamento estratégico. Gomes, Souza e Lunkes (2014) corroboram indicando que as funções exigidas nem sempre são iguais às indicadas pela literatura, sendo as predominantes: gestão de custos, planejamento tributário, planejamento estratégico, contas a pagar e a receber e elaboração de relatórios gerenciais.

Em nível de conhecimento básico, $47,5 \%$ dos acadêmicos se sentem aptos a auxiliar os gestores na tomada de decisão, $45 \%$ a atuar com avaliação financeira e não financeira e $42,5 \%$ a coordenar atividades na área de auditoria. Nos níveis mais baixos de conhecimento, ou pouco conhecimento, atividades relacionadas aos níveis estratégicos como implementar o planejamento estratégico e gerenciar o controle estratégico, foram as mais escolhidas, com $55 \%$ das respostas. Ainda, para atividades como coordenar o alinhamento estratégico, coordenar o desenvolvimento do planejamento estratégico e criar um sistema de incentivos/motivação, 35\%, 30\% e 30\% dos alunos, respectivamente, admitiram não possuir nenhum conhecimento. 
No geral, com relação a todas as atividades listadas, o nível de conhecimento dos graduandos para coordenar estas áreas é baixo $(39,87 \%)$ e básico $(32,63 \%)$, levando em consideração a quantidade de respostas para cada um dos níveis de conhecimento. Ainda, as funções que obtiveram mais respostas com nível de conhecimento elevado não convergem com as mais solicitadas pelo mercado.

Percebe-se ao comparar os resultados das Tabelas 1 e 2 que mesmo tendo cursado a maioria das disciplinas relacionadas às atividades listadas na Tabela 2, os alunos não se sentem aptos a desenvolver tais atividades em uma empresa. $O$ que nos permite inferir que o acadêmico, ao concluir a sua graduação, não se sente preparado para atuar no mercado de trabalho.

Além dos conhecimentos específicos da controladoria, o profissional controller deve possuir o conhecimento em outras línguas para atender as necessidades das empresas cada vez mais globalizadas. Portanto, verifica-se na Tabela 3 o nível de conhecimento dos alunos do curso de ciências contábeis em línguas estrangeiras.

Tabela 3: Nível de conhecimento em língua estrangeira

\begin{tabular}{|l|c|c|c|c|c|}
\hline \multirow{2}{*}{ Língua Estrangeira } & \multicolumn{5}{c|}{ Nível de Conhecimento } \\
\cline { 2 - 6 } & Nenhum & Básico & Médio & Avançado & Fluente \\
\hline Inglês & $5,0 \%$ & $37,5 \%$ & $32,5 \%$ & $22,5 \%$ & $2,5 \%$ \\
\hline Espanhol & $25,0 \%$ & $52,5 \%$ & $17,5 \%$ & $5,0 \%$ & $0,0 \%$ \\
\hline Francês & $97,5 \%$ & $2,5 \%$ & $0,0 \%$ & $0,0 \%$ & $0,0 \%$ \\
\hline Alemão & $90,0 \%$ & $5,0 \%$ & $2,5 \%$ & $2,5 \%$ & $0,0 \%$ \\
\hline Japonês & $100,0 \%$ & $0,0 \%$ & $0,0 \%$ & $0,0 \%$ & $0,0 \%$ \\
\hline Italiano & $95,0 \%$ & $5,0 \%$ & $0,0 \%$ & $0,0 \%$ & $0,0 \%$ \\
\hline
\end{tabular}

Fonte: Dados da pesquisa.

A Tabela 3 representa o nível de conhecimento dos alunos nas línguas estrangeiras mais requisitadas. Em Inglês, 37,5\% dos alunos consideram possuir conhecimento básico; 32,5\% conhecimento médio; $22,5 \%$ conhecimento avançado; e 2,5\% são fluentes. Em Espanhol, a média de conhecimento é básico, sendo representado por 52,5\%. Para as demais línguas listadas, Francês, Alemão, Japonês e Italiano, os alunos demonstraram não possuir nenhum conhecimento, concentrando as suas respostas nessa categoria, com percentuais iguais ou superiores a $90 \%$.

O estudo realizado por Gomes, Souza e Lunkes (2014) identificou a preferência do mercado por profissionais que tenham conhecimento em pelo menos duas línguas, revelando a importância do conhecimento em outro idioma. Ferrari et al (2013) verificou que o inglês sempre foi a língua estrangeira mais solicitada, porém com o passar dos anos houve um aumento nas solicitações por outras línguas, como a espanhola.

Além das qualificações técnicas exigidas, o profissional controller deve possuir algumas características intrínsecas à sua personalidade que podem descrever como ele irá atuar em determinadas situações. As suas características pessoais e técnicas são fundamentais ao exercício pleno das atividades e funções. As características descritas na Tabela 4 são norteadoras para a formação desse perfil desejado.

Tabela 4: Identificação dos acadêmicos quanto às características formadoras do perfil desejado para o controller

\begin{tabular}{|l|c|c|c|c|c|}
\hline \multirow{2}{*}{ Característica } & \multicolumn{5}{c|}{ Identificação } \\
\cline { 2 - 6 } & Nenhum & Pouco & Mediano & Muito & Extremo \\
\hline Pró-atividade & $0,0 \%$ & $0,0 \%$ & $32,5 \%$ & $52,5 \%$ & $15,0 \%$ \\
\hline Liderança & $2,5 \%$ & $12,5 \%$ & $42,5 \%$ & $32,5 \%$ & $10,0 \%$ \\
\hline Relacionamento interpessoal & $0,0 \%$ & $2,5 \%$ & $45,0 \%$ & $32,5 \%$ & $20,0 \%$ \\
\hline
\end{tabular}




\begin{tabular}{|l|c|c|c|c|c|}
\hline Flexibilidade & $0,0 \%$ & $5,0 \%$ & $37,5 \%$ & $37,5 \%$ & $20,0 \%$ \\
\hline $\begin{array}{l}\text { Capacidade de suportar pressão por } \\
\text { resultados }\end{array}$ & $0,0 \%$ & $7,5 \%$ & $52,5 \%$ & $30,0 \%$ & $10,0 \%$ \\
\hline Capacidades e habilidades analíticas & $0,0 \%$ & $17,5 \%$ & $52,5 \%$ & $25,0 \%$ & $5,0 \%$ \\
\hline Habilidades de comunicação & $0,0 \%$ & $17,5 \%$ & $40,0 \%$ & $27,5 \%$ & $15,0 \%$ \\
\hline Conhecimento de negócios & $0,0 \%$ & $32,5 \%$ & $45,0 \%$ & $20,0 \%$ & $2,5 \%$ \\
\hline Conhecimento comportamental & $2,5 \%$ & $30,0 \%$ & $40,0 \%$ & $17,5 \%$ & $10,0 \%$ \\
\hline $\begin{array}{l}\text { Conhecimento de sistemas de } \\
\text { mensuração e avaliação }\end{array}$ & $2,5 \%$ & $37,5 \%$ & $40,0 \%$ & $20,0 \%$ & $0,0 \%$ \\
\hline Firmeza & $0,0 \%$ & $5,0 \%$ & $55,0 \%$ & $25,0 \%$ & $15,0 \%$ \\
\hline
\end{tabular}

Fonte: Dados da pesquisa

Para a maioria das características listadas os graduandos se identificam de forma mediana. Firmeza, capacidade de suportar pressão por resultados e capacidades e habilidades analíticas foram as mais encontradas no nível médio de identificação com 55\%, 52,5\%, 52,5\%, respectivamente. As características que mais se destacaram, por serem identificados como muito presentes nos perfis dos acadêmicos, foram a pró-atividade $(52,5 \%)$ e flexibilidade $(37,5 \%)$.

Percebe-se que grande parte das características mais solicitadas, como capacidade de suportar pressão por resultados, pró-atividade e flexibilidade são encontradas no perfil dos acadêmicos. No entanto, uma característica fundamental para a atuação do profissional - a liderança - apresenta-se apenas de forma mediana com $42,5 \%$.

Através das entrevistas realizadas por Maciel e Lima (2011) com recrutadores na área de Controladoria, identificou-se que as habilidades mais requisitadas envolvem a liderança de equipes e relacionamento, a capacidade de atuar em um ambiente dinâmico e de alta pressão, pró-atividade e visão. Em estudo sobre a necessidade do mercado de trabalho com relação aos profissionais da Controladoria, Calijuri (2004) estudou os mesmos aspectos e os resultados demonstram que a liderança, iniciativa, flexibilidade para mudanças e relacionamento interpessoal são as principais habilidades citadas pelos controllers.

Cursar pós-graduação é apresentado por Calijuri (2004) como altamente necessário para a atuação de um profissional como controller. A mesma pesquisa afirma que $89,7 \%$ dos controllers entrevistados cursaram pós-graduação para manter-se atualizados sobre os conhecimentos em função de suas necessidades e também em função do mercado de trabalho. Gomes, Souza e Lunkes (2014) afirmam que a exigência por pós-graduação é diferenciada para cada um dos três níveis hierárquicos analisados. No nível operacional, $8,27 \%$ requerem profissionais pós-graduados, no nível estratégico, $14,68 \%$, e no nível gerencial, $20,69 \%$.

Tabela 5: Interesse dos graduandos em pós-graduação/especialização

\begin{tabular}{|l|c|c|}
\hline Tipos de Pós-graduação / Especialização & Interessados & $\%$ \\
\hline Especialização- MBA & 21 & $52,5 \%$ \\
\hline Mestrado & 14 & $35,0 \%$ \\
\hline Doutorado & 7 & $17,5 \%$ \\
\hline Não possui interesse & 8 & $20,0 \%$ \\
\hline
\end{tabular}

Fonte: Dados da pesquisa

Corroborando com Calijuri (2004) e Gomes, Souza e Lunkes (2014), a atual pesquisa identifica a importância dos cursos de pós-graduação para o controller. A Tabela 5 apresenta a quantidade de alunos interessados em fazer algum tipo de pós-graduação ou especialização. Pode-se verificar que a maioria dos graduandos, representados por $52,5 \%$, possuem interesse em fazer especialização - 
MBA, seguido de mestrado (35\%) e doutorado (17,5\%). Ainda, $20 \%$ dos questionados responderam não possuir interesse em realizar nenhum tipo de pós-graduação ou especialização.

Dos acadêmicos que responderam possuir interesse em realizar pós-graduação ou especialização, $28,57 \%$ têm interesse em realizar especialização e mestrado; $42,86 \%$ especialização, mestrado e doutorado; $28,57 \%$ mestrado e doutorado.

Através dos resultados é possível inferir que os alunos estão cientes das necessidades e exigências do mercado no que se refere à pós-graduação, sendo a escolha por cursar uma especialização predominante. O resultado é significativo, porém sabendo da crescente disputa das vagas de Controladoria com profissionais de outras graduações, esperava-se que a motivação dos acadêmicos de Ciências Contábeis em manter-se cada vez mais atualizados e ampliar seus conhecimentos fosse maior.

\section{CONCLUSÃO}

As novas perspectivas e exigências do mercado de trabalho com relação ao profissional que atua na área de controladoria motivaram a idealização do presente estudo que tem por objetivo identificar a percepção dos estudantes de Ciências Contábeis sobre seus conhecimentos em Controladoria, além de identificar as características de perfil exigidas do profissional em questão atualmente.

$\mathrm{Na}$ avaliação do conhecimento técnico, a comparação entre as disciplinas cursadas e o nível de conhecimento para atuar na coordenação de determinadas atividades indicou que o fato de ter cursado a disciplina não admite conhecimento ao acadêmico. Percebe-se que mesmo tendo cursado a maioria das disciplinas relacionadas às atividades listadas, os alunos não se sentem aptos a desenvolver tais atividades no ambiente empresarial.

O mercado busca, além das qualificações técnicas, algumas características presentes no perfil do profissional. Foram listadas as características mais procuradas, e através das respostas é possível concluir que os graduandos se identificam, no geral, de forma mediana com cada uma delas. As características que mais se destacaram, por serem identificados como muito presentes nos perfis dos acadêmicos, foram a pró-atividade $(52,5 \%)$ e flexibilidade $(37,5 \%)$, sendo destas, apenas a flexibilidade uma das características listadas por Calijuri (2004) como uma habilidade bastante requisitada. Firmeza, capacidade de suportar pressão por resultados e capacidades e habilidades analíticas foram as mais encontradas no nível médio de identificação com 55\%, 52,5\%, 52,5\%, respectivamente.

Quanto às demais habilidades, os resultados demonstram que o conhecimento em língua estrangeira apresenta-se em nível médio para baixo. Em Inglês, apenas 2,5\% consideram-se fluentes na língua, e $22,5 \%$ possuem conhecimento avançado. Para as demais línguas, a média de conhecimento é básica, e para alguns idiomas, o conhecimento inexistente.

A atualização do conhecimento é uma premissa necessária para qualquer profissional que deseja manter-se em destaque no mercado de trabalho. Os resultados demonstram que essa é uma preocupação presente nos acadêmicos, e que eles estão conscientes da importância de uma pósgraduação. Verifica-se que a maioria dos graduandos $(52,5 \%)$ possui interesse em fazer especialização - MBA, seguido de mestrado (35\%) e doutorado $(17,5 \%)$.

Por fim, conclui-se que o profissional recém-formado não se considera apto para atuar como controller. Percebe-se forte despreparo e pouca confiança com relação às áreas técnicas, e as características mais presentes no perfil dos estudantes não se enquadram naquelas mais solicitadas pelo mercado. 
Sugere-se, para futuras pesquisas, estudar se os resultados encontrados são em decorrência de possíveis falhas no padrão de sistema educacional ou da falta de comprometimento dos acadêmicos diante dos estudos. Ou seja,as disciplinas técnicas e com características práticas como a controladoria, tendem a apresentar conteúdos que estão desalinhados com as práticas das empresas.

\section{REFERÊNCIAS}

BEUREN, I. M.; MOURA, V. M. O papel da controladoria como suporte ao processo de gestão empresarial. Revista Brasileira de Contabilidade, Brasília/DF, v. 29, n.126, p. 59-67, 2000.

BORINELLI, M. L. Estrutura Conceitual Básica de Controladoria: Sistematização à luz da teoria e da práxis. Tese (Doutorado em Ciências Contábeis) - Programa de Pós-graduação em Controladoria e Contabilidade, FEA, USP, São Paulo, 2006.

CALIJURI, M. S. S. Controller - O perfil atual e a necessidade do mercado de trabalho. Revista Brasileira de Contabilidade, n. 150, p.38-53, 2004.

CALIJURI, M. S. S., SANTOS, N. M. B. F.; SANTOS, R. F. Perfil do controller no contexto organizacional atual brasileiro. Artigo apresentado no 9o. Congresso Internacional de Custos. Florianópolis-Brasil: ABC, 2005.

DANIEL, M. M., VESCO, D. G.; TARIFA, M. R. Estudo do perfil, conhecimento, papel e atuação do controller nas cooperativas agropecuárias do estado do Paraná. Artigo apresentado no 7th Congresso USP Controladoria e Contabilidade. São Paulo, Brasil, 2007.

FACHINI, G. J.; BEUREN, I. M.; NASCIMENTO, S. Evidências de isomorfismo nas funções da controladoria das empresas familiares têxteis de Santa Catarina. In: CONGRESSO BRASILEIRO DE CUSTOS, Fortaleza. Anais... Fortaleza, 2009.

FERRARI, M. J., CUNHA, L. C., LUNKES, R. J.; BORGERT, A. O perfil do controller sob a ótica do mercado de trabalho nacional. Revista de Informação Contábil Vol. 7(3), 2013, p.25-50.

GIONGO, J.; NASCIMENTO, A. M. O envolvimento da controladoria no processo de gestão; um estudo em empresas industriais do estado do Rio Grande do Sul. In: IX CONGRESSO INTERNACIONAL DE CUSTOS, Florianópolis. Anais... Florianópolis: Associação Brasileira de Custos, 2005.

GOMES, C. V.; SOUZA, P. de; LUNKES, R. J. O perfil do profissional da controladoria solicitado por empresas brasileiras. GCG - Revista de Globalização, Competitividade e Governabilidade, Madrid, v. 8, n. 1, p.34-50, jan./abr.. 2014.

ICV-IGC - Internationaler Controller Verein and Internatinal Group of Controlling. The Essence of Controlling - the Perspective of the Internationaler Controller Verein (ICV) and the Internatinal Group of Controlling (IGC). JournalManagement Control, 23, 2013, p. 311-317.

LAKATOS, E. M.; MARCONI, M. de A. Metodologia científica: ciência e conhecimento cientifico, métodos científicos, teoria, hipóteses e variáveis. São Paulo: Atlas, 2007.

LUNKES, R. J.; SCHNORRENBERGER, D. Controladoria: Na coordenação dos sistemas de gestão. São Paulo: Atlas, 2009. 181 p.

LUNKES, R. J.; MACHADO, A.; ROSA, F. S.; TELES, J. Funções da Controladoria: um estudo nas 100 maiores empresas do estado de Santa Catarina. Análise Psicológica, Vol. 29: 2011, p. 345-361. 
LUNKES, R. J.; SCHNORRENBERGER, D.; ROSA, F. S. da. Funções da controladoria: uma análise no cenário brasileiro. Revista Brasileira de Gestão de Negócios, São Paulo, v. 15, n. 47, p.283-299, abr./jun.. 2013.

LUNKES, R. J.; SCHNORRENBERGER, D.; SOUZA, C. M. de; ROSA, F. S. da. Análise da Legitimidade Sociopolítica e Cognitiva da Controladoria no Brasil. Revista de Contabilidade e Finanças, São Paulo, v. 23, n. 59, p.89-101, maio 2012.

LUNKES, R. J.; VICENTE, E. F. R.; FABRE, V. V.; SOUZA, C. M. de; TEIXEIRA, A. O.; JÚNIOR, J. C. T.. A disciplina de controladoria e sua inclusão nos cursos de ciências contábeis. Revista de Contabilidade do Mestrado em Ciências Contábeis da UERJ, Rio de Janeiro, v. 14, n. 2, p.32-49, maio, 2009.

MACIEL, L. F.; LIMA, R. A. O perfil ideal do controller nas condições que se apresentam o mercado de trabalho no Brasil, In. ENCONTRO LATINO AMERICANO DE INICIAÇÃO CIENTÍFICA, 15., ENCONTRO LATINO AMERICANO DE PÓS-GRADUAÇÃO, 11., Paraíba. Anais... Paraíba, 2011.

MEDEIROS, C. S. C.; RABELO, E. C. O perfil da controladoria em concessionárias de veículos do município de Tubarão (SC). Artigo apresentado no 17․ Congresso Brasileiro de Custos 2010, Belo Horizonte, Brasil, 2010.

MOSIMANN, C. P.; FISCH, S. Controladoria: seu papel na administração de empresas. 2. ed. São Paulo: Atlas, 1999.

OLIVEIRA, L. R. de; PONTE, V. M. R. O papel da controladoria nos fundos de pensão. In: IX CONGRESSO INTERNACIONAL DE CUSTOS, Anais...Florianópolis: Associação Brasileira de Custos, 2005.

ORO, I. M.; DITTADI, J. R.; CARPES, A. M. S.; BENOIT, A. D. O perfil do profissional de controladoria sob a óptica do mercado de trabalho brasileiro. Pensar Contábil, Vol.1, 2009, p.5-15.

PELEIAS, I. R.; MENDONÇA, J. de F.; SLOMSKI, V. G.; FAZENDA, I. C. A. Interdisciplinaridade no Ensino Superior: Análise da percepção de professores de controladoria em cursos de ciências contábeis na cidade de São Paulo. Avaliação, Campinas, v. 16, n. 3, p.499-532, nov. 2011.

PEREIRA, E.; KOBAYASHI, A.; ARAGAKI, C.; GONÇALVES, R.; MOMPEAN, V.; LIMA, J. R. de. Fundamentos da contabilidade. São Paulo: Prentice Hall, 2005.

RAUPP, F. M.; BEUREN, I. M.; LONGARY, A. A.; SOUZA, M. A. B. de; COLAUTO, R. D.; PORTON, R. A. de B. Como Elaborar Trabalhos de Monografias em Contabilidade. In: BEUREN, Ilse Maria. (ORG.). Metodologia da Pesquisa Aplicável às Ciências Sociais: Raupp e Beuren. São Paulo: Atlas, 2003.

RESOLUÇÃO CNE/CES 6, DE 25 DE SETEMBRO DE 2009. Estabelece normas para o funcionamento de cursos de pós-graduação. Resolução. Portal CNE, Disponível em: <http://portal.mec.gov.br/dmdocuments/rces006_09.pdf>. Acesso em: 22 out. 2014.

RESOLUÇÃO CNE/CES 10, DE 16 DE DEZEMBRO DE 2004. Institui as diretrizes curriculares nacionais para o curso de graduação em Ciências Contábeis, bacharelado, e dá outras providências. Resolução. Portal CNE, Disponível em: <http://portal.mec.gov.br/cne/arquivos/pdf/rces10_04.pdf>. Acesso em: 22 out. 2014.

RICHARDSON, R. J.; et al. Pesquisa social: métodos e técnicas. São Paulo: Atlas, 2008.

SANTOS, R.V.; CASTELLANO, A.C. F.; BONACIM, C. A. G.; SILVA, L. P.O papel do controller em empresas de grande porte. Artigo apresentado no 12‥ Congresso Brasileiro de Custos 2005, Florianópolis, Brasil, 2005. 
SANTOS, S. M.; MAGALHÃES, D. C.; LUCA, M. M. M.; PESSOA, M. N. M. \& CABRAL, A. C.A Controladoria Como Suporte Ao Processo De Gestão Das Grandes Empresas Do Estado Do Ceará Um Estudo Em Empresas Ganhadoras De Prêmio Delmiro Gouveia. Artigo apresentado no 15ㅇ. Congresso Brasileiro de Custos 2008, Curitiba, Brasil, 2008.

SCHNORRENBERGER, D.; RIBEIRO, L. M. S.; LUNKES, R. J.; GASPARETTO, V. Perfil do controller em empresas de médio e grande porte da grande Florianópolis. 14ㅇ. Congresso Brasileiro de Custos, João Pessoa, Brasil, 2007.

SIQUEIRA, J. R. M. de; SOLTELINHO, W. O profissional de controladoria no mercado brasileiro: do surgimento da profissão aos dias atuais. Revista Contabilidade \& Finanças. São Paulo, SP, v. 12, n. 27, p. 66-77, dez. 2001.

SOUZA, B. C.; BORINELLI, M. L. As funções de controladoria: um estudo a luz dos anúncios das empresas de recrutamento de profissionais, In: CONGRESSO BRASILEIRO DE CUSTOS, 10, Fortaleza. Anais... Fortaleza: ABC, 2009.

WEBER, J. The development of controller tasks: explaining the nature of controllership and its changes. Journal of Management Control, Alemanha, v. 22, n. 1, p.25-46, set. 2011. 